\title{
Towards Sustainable Intensification of Crop Production-Yield Gaps and Water Use Efficiency in Farming Systems
}

\author{
Anita Ierna (D) \\ Institute of BioEconomy, National Research Council of Italy (CNR-IBE), via P. Gaifami 18, 95126 Catania, Italy; \\ anita.ierna@cnr.it
}

check for updates

Citation: Ierna, A. Towards Sustainable Intensification of Crop Production-Yield Gaps and Water Use Efficiency in Farming Systems. Agronomy 2021, 11, 710. https:// doi.org/10.3390/agronomy11040710

Received: 11 March 2021

Accepted: 31 March 2021

Published: 8 April 2021

Publisher's Note: MDPI stays neutral with regard to jurisdictional claims in published maps and institutional affiliations.

Copyright: (C) 2021 by the author. Licensee MDPI, Basel, Switzerland. This article is an open access article distributed under the terms and conditions of the Creative Commons Attribution (CC BY) license (https:// creativecommons.org/licenses/by/ $4.0 /)$.
The primary objective of any cropping system continues to be increasing the productivity and profitability of crops. In the last decades, many advances have been made regarding sustainable crop production intensification, mainly with the aim of increasing or maintaining yield. However, the available water around the world is decreasing due to greater population growth, and the competing demands from industry and urban development. The changing climate, with a gradual but continuous rise in temperatures and the evapotranspiration demand of crops, which tends to generate an increase in water requirements, adds further complexity to water management. Consequently, as the main consumer of fresh water, agriculture is currently faced with the challenge of finding new approaches that can ensure the protection of water resources and their integrity. The efficiency of the use of the available water, namely, the proportion of available water directed towards plant transpiration is often $<50 \%$. Consequently, such a proportion gives room for potential improvements in crop water use efficiency (WUE). The possible improvement in WUE requires first of all considering the adaptability of the crop to the environment, and the water use efficiency of the crop. The breeding or selection of genotypes, which could be more efficient in water use, may represent an important strategy and a long-term solution to the problem of water scarcity. This is especially important for non-food crops, such as Miscanthus, an important perennial biomass crop for which it would be important to select genotypes with a tolerance to droughts. This special issue focuses on the recent advancements in research involving the screening and individuation of Miscanthus genotypes that, for their response to droughts, are more resilient to climate change for the sustainable development of biomass crops. Among perennial biomass crops with C4 photosynthesis, Miscanthus combine high-yield potentials and water use efficiencies. However, the standard commercial clone, $M$. $x$ giganteus $(M x g)$, is not well suited to areas with a limited water supply and extreme summer droughts, such as the southern Mediterranean [1]. For this reason, a diverse panel of thirteen Miscanthus genotypes ( $M$. sinensis, $M$. floridulus, $M$. sacchariflorus and $M x g$ ) has been screened to identify which types could maximize yield under the typical summer drought conditions of the South Mediterranean climate. The genotypes were grown and analyzed under full water restoration (applying 100\% of the maximum evapotranspiration) and rainfed regimes. The Miscanthus genotypes studied showed a good range of adaptability to semi-arid Mediterranean conditions, expressing the main physiological traits associated with $\mathrm{C} 4$ crops, such as high photosynthetic rates, biomass yields and water use efficiencies. However, the diversity found among the germplasm tested, the temporal variation in net photosynthesis, stomatal conductance, transpiration rate and instantaneous water use efficiency, demonstrated the presence of different strategies between the genotypes. The selections from $M$. floridulus and $M$. sinensis were better adapted to the rainfed conditions and could produce six times more biomass than M. $x$ giganteus, hence their use as parents in the experimental breeding aimed at producing future seed-based drought-resilient hybrids. To deepen knowledge on the traits associated with sustaining Miscanthus biomass production under drought stress, research [2] was planned in which the commercial hybrid M. $x$ giganteus, and high-yielding examples from 
the parental species $M$. sinensis and M. sacchariflorus, were grown under well-watered and moderate drought conditions. Growth, morphology, physiology and phenotypic plasticity were analyzed. In the well-watered plants, variance in the yield was explained by a relatively simple empirical model including stem length and stem number, whereas under drought conditions a more complex model was needed, including the addition of a leaf area and stomatal conductance data. The traits that most contributed to the accumulation of a higher biomass in optimal and in droughted conditions were stem number and canopy height. The selection for superior performance per se, under more optimal conditions, appears to be a viable strategy and perhaps the most practical one given the extraordinary diversity in the severity and duration of drought stress possible in the natural environment. This knowledge can help define ideotypes for drought tolerance and develop Miscanthus varieties that sustain high yields across a range of environmental conditions.

On the other hand, the water scarcity and the incremental rise in irrigation costs have led to a growing interest in improving the productivity of water use in crop production. The limited availability of irrigation water worldwide requires fundamental changes in irrigation management and the application of water-saving strategies. One way of optimizing WUE to achieve higher crop yields per unit of irrigation water is deficit irrigation, the deliberate and systematic under-irrigation of crops. The effective use of deficit irrigation requires a prior and precise knowledge of crop response to drought stress, as drought tolerance varies considerably with genotype. To study the possibility of producing African leafy vegetables under limited water conditions, a trial [3] was carried out involving three selected vegetables: Vigna unguiculata (cowpea), Corchorus olitorius (jute mallow), Amaranthus cruentus (pigweed) and a reference vegetable crop, Beta vulgaris, under varying water regimes $(30 \%, 60 \%$ and $100 \%$ of crop water requirement (ETc)). Using $60 \%$ ETc was suitable for the production of $A$. cruentus, C. olitorius and B. vulgaris var. cicla, whereas $30 \%$ ETc was recommended for $V$. unguiculata. Moreover, $V$. unguiculata was stable for all measured parameters across the varying water regimes and performed better than other African leafy vegetables, including B. vulgaris. Overall, the results of this study indicate that the African leafy vegetables had a higher degree of drought tolerance than the reference crop, $B$. vulgaris. The ranking for drought tolerance, starting with the most tolerant, could be as follows: V. unguiculata, C. olitorius, A. cruentus and B. vulgaris. Concerning guar (Cyamopsis tetragonoloba (L.) Taub.), an important legume species for seed galactomannans and widely used in food industries, but also for paper, textiles, oil well drilling and fracking, little research has been conducted to evaluate and quantify how much drought severity may affect the yield potential. In a field experiment in a semi-arid environment, the effects on five cultivars (Kinman, Lewis, Matador, Monument, and Santa Cruz) of the following three different irrigation regimes were studied: $100 \%$ (fully irrigated), $50 \%$ and $25 \%$ of soil water deficit replenishment on seed yield and WUE [4]. The results highlighted that guar has a high-yield potential when irrigated at 100\% soil water deficit replenishment, but imposing $50 \%$ of water deficit may be a good strategy, allowing a low decrease in seed yield and an increase in WUE. Moreover, the cultivars showed different yield performance in response to the water regimes, with Lewis and Santa Cruz showing the highest seed yield and the highest number of pods per plant under fully watered and water-limited conditions. Moreover, drought tolerance may vary with phenological stage, so one way of reducing the water amount is to limit its applications to the drought-sensitive growth stage of a crop (regulated deficit irrigation). In processing tomatoes to assess the physiological and agronomic responses to deficit irrigation applied at critical stages, a field experiment was conducted in a coastal site of southern Italy, where seven irrigation treatments, differing in daily evapotranspiration (ETc) restored (100\%-full or 50\%-deficit), and the time of watering (long-season or limited to the vegetative period or to flowering), were applied to cv. Hypeel $F_{1}$ [5]. Predawn water potential appeared to be a more reliable parameter than leaf transpiration and stomatal conductance under dry climatic conditions, because it was much less affected by vapor pressure deficit. In tomatoes, irrigation for the whole season was important to maximize the fruit yield. However, a balance between the improved 
irrigation water use efficiency (IWUE) and the satisfactory yield can be achieved through a moderate water stress induced by irrigation at a 50\% ETc rate. The flowering stage has been confirmed as sensitive to drought stress, so that when irrigation water is scarcely available it could be omitted during the vegetative stage and limited (at a reduced rate, e.g., $50 \%$ ETc) to the flowering period, keeping in mind that water saving is more or less proportional to yield losses. The development of water-saving irrigation strategies may encourage farmers to revise their irrigation scheduling approach towards more efficient water management, in order to limit water consumption and achieve satisfactory yields.

There has also been a need to understand the effects of the combination of irrigation water management with other agronomic practices, which can interact notably with water saving and towards improved WUE. Among these are the sowing time, which changing rainfall and temperature conditions can play a key role in water stress, water saving, and therefore WUE. In a potato crop in a Mediterranean environment, the effects of moderate water stress compared to well-watered conditions (supplying 50 or $100 \%$ of the maximum evapotranspiration (ETm)) on tuber yield and WUE indices were evaluated in two planting dates (early and late), differing by almost one month [6]. Supplying $50 \%$ of the ETm induced only moderate water deficits, so it, compared to well-watered conditions, reduced the yield slightly but increased the IWUE considerably, allowing to save large amounts of irrigation water $\left(650 \mathrm{~m}^{3} \mathrm{ha}^{-1}\right.$ in the early planting and $550 \mathrm{~m}^{3} \mathrm{ha}^{-1}$ in the late planting). The research has substantially highlighted that the moderate water stress had a lesser effect in the late planting date, in which the plants made better use of the water than in the early planting, allowing further improvements in IWUE. Overall, research findings suggest the importance of considering water management and planting dates simultaneously to reach the largest amount of irrigation water saved and therefore the highest WUE. In quinoa (Chenopodium quinoa Willd.), a potential nutritious crop for human consumption, seed yields under moderate management are quite low. To meet the increasing global demand, yield potential may be attained by simultaneously optimizing irrigation, nitrogen fertilization and plant density. To verify this hypothesis, two years of field experiments were undertaken to investigate the effects of the irrigation onset criteria using three soil matric potentials (SMP) $(-15,-25$, and $-55 \mathrm{kPa})$, three nitrogen fertilizer rates $(80,160$, and $\left.240 \mathrm{~kg} \mathrm{ha}^{-1}\right)$, and three plant densities $\left(20,30\right.$, and 40 plants $\mathrm{m}^{-2}$ ) on quinoa seed yield and quality [7]. The $-55 \mathrm{kPa}$ SMP irrigation onset criteria treatment resulted in notable water stress, whereas applying irrigation when the soil matric potential immediately reached -15 or $-25 \mathrm{kPa}$ obtained very good seed yield and quality. The plant density of 30 plants $\mathrm{m}^{-2}$ is recommendable for quinoa cultivation. With the highest nitrogen fertilizer rate $\left(240 \mathrm{~kg} \mathrm{ha}^{-1}\right)$, the greatest thousand seed weight and protein content was achieved. It is worth noting that in this trial, quinoa plants also consumed most of the available nitrogen in the soil especially with sufficient water and high plant density, suggesting that they have an astonishingly high nitrogen requirement and should be cultivated in a crop rotation system to maintain the balance of soil nitrogen.

This special issue focuses on the recent advancements in the wide field of the sustainable intensification of crop production by the screening of drought-tolerant Miscanthus genotypes and water-saving strategies, deficit irrigation in particular, not only in food crops, such as potato, tomato, leafy vegetables and quinoa, but also in industrial species such as guar. All the papers in this special issue have attracted significant attention, as can be seen by the graphs for each paper on the journal's homepage. It is hoped that it will encourage others to use these tools in developing an even wider range of strategies for the sustainable intensification of crop production.

Funding: Experimental work of A.I. in the Institute of BioEconomy, National Research Council of Italy received no external funding.

Acknowledgments: The author is grateful to Alfio Fallica for his administrative support.

Conflicts of Interest: The author declares no conflict of interest. 


\section{References}

1. Scordia, D.; Scalici, G.; Clifton-Brown, J.; Robson, P.; Patanè, C.; Cosentino, S.L. Wild Miscanthus Germplasm in a DroughtAffected Area: Physiology and Agronomy Appraisals. Agronomy 2020, 10, 679. [CrossRef]

2. Malinowska, M.; Donnison, I.; Robson, P. Morphological and Physiological Traits that Explain Yield Response to Drought Stress in Miscanthus. Agronomy 2020, 10, 1194. [CrossRef]

3. Maseko, I.; Ncube, B.; Tesfay, S.; Fessehazion, M.; Modi, A.T.; Mabhaudhi, T. Productivity of Selected African Leafy Vegetables under Varying Water Regimes. Agronomy 2020, 10, 916. [CrossRef]

4. Avola, G.; Riggi, E.; Trostle, C.; Sortino, O.; Gresta, F. Deficit Irrigation on Guar Genotypes (Cyamopsis tetragonoloba (L.) Taub.): Effects on Seed Yield and Water Use Efficiency. Agronomy 2020, 10, 789. [CrossRef]

5. Patanè, C.; Corinzia, S.A.; Testa, G.; Scordia, D.; Cosentino, S.L. Physiological and Agronomic Responses of Processing Tomatoes to Deficit Irrigation at Critical Stages in a Semi-Arid Environment. Agronomy 2020, 10, 800. [CrossRef]

6. Ierna, A.; Mauromicale, G. How Moderate Water Stress Can Affect Water Use Efficiency Indices in Potato. Agronomy 2020, 10, 1034. [CrossRef]

7. Wang, N.; Wang, F.; Shock, C.C.; Meng, C.; Qiao, L. Effects of Management Practices on Quinoa Growth, Seed Yield, and Quality. Agronomy 2020, 10, 445. [CrossRef] 